\section{Original article}

Institute of Tropical Medicine, Antwerp, Belgium

F Crabbé

M Laga

Population Service

International,

Washington DC, USA

J P Tchupo

T Manchester

T Gruber-Tapsoba

J Timyan

AIDS Control and Prevention Program, Family Health International,

Washington DC, USA

D Mugrditchian

G Goodridge

G Dallabetta

Institut de Recherche et d'Etudes des Comportements, Yaoundé, Cameroon C Cheta

Correspondence to: François Crabbé, STD/AIDS Research and Intervention Unit, Institute of Tropical Medicine, Nationalestraat 155, B-2000 Antwerp, Belgium.

Email: fcrabbe@itg.be

\title{
Prepackaged therapy for urethritis: the "MSTOP" experience in Cameroon
}

\author{
F Crabbé, J P Tchupo, T Manchester, T Gruber-Tapsoba, D Mugrditchian, J Timyan, \\ G Goodridge, C Cheta, M Laga, G Dallabetta
}

Rationale: The social marketing of STD treatment may be a strategy to increase the availability of effective therapy for urethritis in male patients.

Objective: To evaluate a pilot project of social marketing of urethritis treatment packages. The project, initially designed for over the counter sale in private pharmacies, was finally restricted by national health authorities to primary healthcare settings in Yaoundé and Douala, Cameroon.

Methods: Monthly sales of packages containing antibiotics, condoms, partner referral cards, and written information on STDs were monitored by the social marketing agency. Structured interviews were conducted with a sample of traceable patients who had consulted for urethritis. Structured interviews completed by focus group discussions were conducted among healthcare providers. Interview findings were further validated by a "mystery patient" survey, using surrogate patients. Lastly, 15 key informants among the decision makers involved in the project were interviewed in depth. Local independent consultants carried out the whole evaluation.

Results: A total of 1392 treatment packages were sold in 10 months. Patients who had purchased the package reported high compliance with the treatment, with $99 \%$ taking the single dose of cefuroxime-axetil and $83 \%$ completing the course of doxycycline. $76 \%$ notified all or some partners, and $84 \%$ of those who had sex during treatment used condoms. In contrast, only $27 \%$ of trained healthcare providers prescribed "MSTOP". They questioned the omission of laboratory diagnosis, the selection of antibiotics, and the duration of therapy. Public health authorities were also sceptical about the choice of antibiotics and viewed the initial project as an overt encouragement of self medication.

Conclusions: Although the MSTOP project was not implemented in the way it had initially been designed, it highlighted the patients' interest in the product. Public health authorities in Cameroon should have been made aware of the limitations of the formal sector's response to STD care among men before over the counter sale of prepackaged therapy could have been considered as an alternative approach to inadequate self medication. (Sex Transm Inf 1998;74:249-252)

Keywords: urethritis; social marketing; Cameroon

\section{Introduction}

Prompt treatment of sexually transmitted diseases (STDs) both prevents individual complications and reduces community transmission of STDs and human immunodeficiency virus (HIV) infection. ${ }^{12}$ However, STD case management in the formal sector can only be as effective as the coverage achieved by formal health services. Health seeking behaviour depends on health service delivery as well as patient characteristics. ${ }^{3}$ A 1992 survey in Cameroon showed that male urethritis management in the formal sector was expensive, ineffective, and time consuming, driving nearly $50 \%$ of patients to self treatment. ${ }^{4}$ Health services also face competition from the informal sale of medicines, which is common in many areas of the world. In Cameroon, no fewer than six categories of informal drug vendors cater to self medicating patients.

In 1991 social marketing of prepackaged STD therapy for male urethritis was introduced in Cameroon. The five original objectives of this innovative approach to STD treatment were to: (a) improve the ability of healthcare providers to prescribe effective STD antibiotic regimens to their clients by training them to follow STD diagnosis and treatment guidelines; (b) improve the delivery of STD treatment and prevention by marketing special treatment packages at an acceptable price in the formal health and pharmaceutical sectors; (c) improve patient compliance by including a single dose drug for gonorrhoea and a 10 day course of antibiotic therapy for chlamydial urethritis in one package; (d) increase the use of condoms in STD prevention by including them in the treatment package; (e) encourage partner notification with referral cards.

In this paper, we report on the results of the evaluation of the pilot phase of the project.

\section{Material and methods}

THE “MSTOP” KIT

An STD treatment package was developed and pretested with potential consumers to address the syndrome of acute urethritis in men. Acute urethritis in male patients was selected for the pilot phase because it is a common STD in Cameroon, ${ }^{6}$ with symptoms bothersome enough to prompt patients to seek treatment immediately in the formal or informal sector. Urethritis can also be successfully treated with oral antibiotics. The kit bore the name of "MSTOP", for "stop MST" (MST is the French acronym for STD). A black vinyl pouch 
contained two $500 \mathrm{mg}$ tablets of cefuroximeaxetil and 20 capsules of $100 \mathrm{mg}$ of doxycycline to treat uncomplicated gonococcal and chlamydial infection. It also included an educational leaflet on STDs entitled "Everything you should know about STDs" with instructions on how to take the medicine, two partner referral cards, and eight condoms. Cefuroxime-axetil was selected for gonococcal infection because it is effective in single oral dose and devoid of any serious side effect, and because it was available in the country. ${ }^{7-9}$ The WHO and CDC recommended cefixime was not registered for use in Cameroon, and ciprofloxacin is contraindicated in pregnancy. ${ }^{10}{ }^{11}$ Treatment packages intended for women referred by male index patients contained cefuroxime-axetil and erythromycin. The 10 day course of doxycycline was set in agreement with the ministry of health. The cost price of the kit was $\$$ US13.5 (75\% represented the cost of the drugs on the national market and $25 \%$ packaging and selling costs). Doxycycline was particularly expensive compared with international prices because Cameroonian drug regulations prohibited the commercialisation of non-branded products. ${ }^{12}$ The retail price of the kit was set at set at Cameroonian francs (FrC) 5000 or $\$ 17$.

THE PILOT PHASE

The kit was originally developed for sale in the formal public and private health sectors and over the counter in private pharmacies in Yaoundé and Douala, the country's two major cities. The interest of the ministry of health was high in the beginning, but the departure of a key decision maker within the ministry during the baseline data collection phase resulted in less support for the project, limiting it to a pilot phase which started in July 1993. MSTOP was made available on prescription in 22 healthcare units and three private pharmacies selected by the ministry of health. The settings were located within or near military and university grounds.

Syndromic management of STDs had not yet been implemented in Cameroon. This approach was still very new to public health decision makers. A half day training course was therefore given to 81 healthcare providers (medical doctors and nurses) working within the project's settings. Healthcare providers were informed about the interaction of STDs and HIV and about the syndromic management of urethritis, before being instructed in the project's methodology.

Kits were supplied at wholesale price to the health centre or private pharmacies, which in turn sold them to the patients with a standard profit margin. In health facilities where there was no pharmacy, practitioners sold kits directly to patients. The 10 month pilot project ended in March 1994.

EVALUATION OF THE PILOT PROJECT

Five different approaches were used to evaluate the project.
(1) Monthly sales of MSTOP kits were monitored in each setting by the social marketing agency.

(2) A quantitative survey was conducted among a convenience sample of 141 traceable patients from the 979 whose names and addresses were confidentially recorded when being prescribed MSTOP. After giving informed consent, these patients were interviewed by trained social science students using a standard, pretested questionnaire. The questions concerned perceptions of the MSTOP package, perceived efficacy of the medication, compliance with the treatment, value of the educational materials, and use of condoms and partner referral cards.

(3) Qualitative and quantitative information was obtained from a convenience sample of 46 of the 81 trained healthcare providers through focus group discussions and structured interviews. The remaining 35 could not be evaluated because they had been moved to other settings and replaced by healthcare workers unfamiliar with the project. Questions were asked about the achievements of the project, perceptions of the MSTOP concept, problems encountered, and suggestions for improvements.

(4) A “mystery patient" survey using surrogate patients was used to validate the interview findings. Volunteer university students were trained to pose as STD patients seeking treatment for urethral discharge at the participating clinics. The survey included 47 trained providers as well as a convenience sample of 47 providers working at the same health facilities but who did not participate in the initial training. Mystery patients collected information on the duration of consultation, history taking, prescription of laboratory tests and medication, as well as on duration and content of preventive counselling. The information was recorded on a standard report form immediately after leaving the health facility.

(5) Qualitative data were collected by an independent consultant through in depth interviews with $15 \mathrm{key}$ informants who were either medical or public health decision makers involved in the project. These interviews addressed the MSTOP concept, the development of the project, any perceived problem, and suggestions for the future.

\section{Results}

SALES OF MSTOP KITS

A total of 1392 kits were sold in a 10 month period; 552 in 12 health facilities in Yaoundé, 779 in 10 health facilities in Douala, and 61 in the three pharmacies. Sales remained fairly constant throughout the project. They dropped in November and December 1993 when civil servants had their salaries abruptly reduced by more than 50\%, but recovered in January 1994 as the price remained unchanged even after the devaluation of the FrC. Sales varied considerably among health facilities, however, because of wide variations in patient attendance and healthcare providers' motivation. For each health facility total sales ranged from five to 360 , with a median of 37 kits. In the most 
Table 1 Survey among 141 patients on their perceptions of "MSTOP"

\begin{tabular}{ll}
\hline & $\%$ \\
\hline Sociodemographic data: & \\
$\quad$ Military/students & 62 \\
Other & 38 \\
Sex & 23 \\
Female users & \\
"How did you like the kit?” & 87 \\
Handy & 73 \\
Attractive & 76 \\
Acceptable price & 57 \\
Everything included & 18 \\
Expensive & 10 \\
Incomplete & 86 \\
Read the educational leaflet & \\
Complied with treatment & 99 \\
Cefuroxime-axetil & 83 \\
Doxycycline & 26 \\
Had sex while on treatment & 84 \\
Used condoms (if sex) & \\
Notified partners & 53 \\
All partners & 23 \\
Some partners & 23 \\
No partner & \\
\hline *Answers not mutually exclusive. &
\end{tabular}

actively participating health centre, about half of the patients with urethritis were treated with MSTOP. In the other settings proportions were lower but could not be assessed because incoming patients were not registered.

SURVEY AMONG MSTOP USERS

Of the 141 MSTOP users $62 \%$ were students or servicemen, while the remainder were patients' relatives or acquaintances (table 1). Twenty three per cent were female partners of index patients. When asked: "How do you like the package?" $10 \%$ reported that it was "incomplete" because drugs for syphilis or trichomoniasis were missing. Of the $86 \%$ of users who read the leaflet, $90 \%$ were pleased. The remaining $10 \%$ criticised the complexity of the message or the layout. Virtually all patients took the cefuroxime-axetil, and $83 \%$ complied with the doxycycline treatment. Fifty three per cent reported having notified all their partners; an additional $23 \%$ reported having notified some. Of the 165 notified partners, $44 \%$ were contacted with the partner referral card and the remaining $56 \%$ by other means. There was no way of verifying that the notified contacts were actually treated.

SURVEY AMONG HEALTHCARE PROVIDERS

At the interview $72 \%$ of the healthcare providers said that the objectives of the project had

Table 2 "Mystery patient" survey among trained and untrained healthcare providers on the quality of urethritis management

\begin{tabular}{|c|c|c|c|}
\hline & $\begin{array}{l}\text { Trained } \\
(n=44)\end{array}$ & $\begin{array}{l}\text { Untrained } \\
(n=46)\end{array}$ & $p$ Value \\
\hline \multicolumn{4}{|l|}{ Prescription behaviour: } \\
\hline Requested lab tests beforehand & $9(20 \%)$ & $13(28 \%)$ & \\
\hline Prescribed "MSTOP" & $12(27 \%)$ & $(-)$ & NA \\
\hline Prescribed other antibiotics than "MSTOP" & $23(53 \%)$ & $33(72 \%)$ & NA \\
\hline Median duration of consultation & 7 minutes & 8 minutes & \\
\hline Median duration of counselling & 4 minutes & 4 minutes & \\
\hline Prevention messages: & $(n=46)^{\star}$ & $(\mathrm{n}=47)$ & \\
\hline Treatment compliance & $23(50 \%)$ & $26(55 \%)$ & NS \\
\hline $\begin{array}{l}\text { Avoid sexual relations or use condoms during } \\
\text { treatment }\end{array}$ & $11(24 \%)$ & $23(50 \%)$ & 0.01 \\
\hline Use condoms in casual sex & $6(12 \%)$ & $13(27 \%)$ & NS \\
\hline Notify partner & $15(31 \%)$ & $18(34 \%)$ & NS \\
\hline Reduce risk behaviour & $23(50 \%)$ & $28(60 \%)$ & NS \\
\hline
\end{tabular}

${ }^{\star} \mathrm{A}$ total of 94 prescribers were surveyed, 47 trained and 47 untrained. Ninety three records were available for analysis of prevention messages, and 90 for analysis of prescription behaviour. been fulfilled. Ninety four per cent reported that the project deserved to be extended. No difference was found between doctors and nurses. In contrast, focus group discussions revealed the healthcare providers' feeling that urethritis should not be treated without laboratory confirmation. They also raised concerns about the choice of antibiotics and duration of treatment. Some did not believe in single dose therapy, while others suggested extending the doxycycline therapy to 14 or 21 days. Financial incentives to sell the kit were considered inappropriate, as practitioners usually receive promotional material or free drugs from pharmaceutical companies.

MYSTERY PATIENT SURVEY

The findings of the mystery patient survey among trained and untrained healthcare providers are shown in table 2 . Of the trained practitioners, only $27 \%$ prescribed MSTOP. Respectively, $20 \%$ and $28 \%$ of the trained and untrained practitioners requested laboratory testing. About half of the patients received one or more prevention messages. No difference was observed between trained and untrained practitioners, except for the recommendation to abstain from sexual relations during the treatment. The result was paradoxically better in the untrained group $(p=0.01)$. Of a total of 56 prescriptions of antibiotics other than MSTOP, 48 were fully readable and analysed. Only five $(10.4 \%)$ were correct for both gonococcal and chlamydial infections. The remaining 43 either lacked antibiotherapy for one of the two pathogens, listed a wrong drug or regimen, or included unnecessary drugs such as urinary antiseptics. No difference in prescription behaviour was found between trained and untrained healthcare providers.

IN DEPTH INTERVIEWS WITH KEY INFORMANTS Interviews with public health decision makers and other key informants involved in the project revealed that they were well aware of the objectives of the project. They were reluctant to support it, however, because they felt that they had not been sufficiently involved in the research and development of the kit in spite of the 18 month preparatory phase. Disagreement about the appropriateness of the selected antibiotics was exacerbated by the lack of official STD treatment guidelines. Some decision makers also criticised the promotion of prepackaged therapy as an open support for self medication.

\section{Discussion}

With a total sale of 1392 treatment packages after 10 months - that is, about one treatment package per health facility and per week, the project fell short of the implementers' expectations. At least some of the reasons for low sales were identified by the evaluation. While MSTOP was well received by the users, healthcare providers were more cautious about the product. The mystery patient survey revealed that only $27 \%$ of those who had been trained actually prescribed MSTOP. 
Most MSTOP users showed great interest in the presentation of curative and preventive materials together. Treatment compliance was $99 \%$ and $83 \%$ with the cefuroxime-axetil and doxycycline respectively. Patients read the leaflet and used the condoms and partner referral cards. The price was considered affordable by most, especially after the devaluation of the FrC. However, the survey only included patients who had purchased the kit.

In contrast, healthcare providers expressed interest in MSTOP but felt it threatened their liberty to order laboratory tests and prescribe drugs of their choice. The half day training was not sufficient to convince them of the benefits of syndromic management of urethritis and had no effect on prevention messages. Acceptance of MSTOP was also hampered by the lack of official STD treatment guidelines in Cameroon. Healthcare providers viewed MSTOP as just one treatment option among many.

Lower than expected sales could also be attributed to other factors. The package was perceived as expensive before the devaluation, notably by public health decision makers. However, preliminary surveys indicated that patients with urethritis were charged a median price of $\$ 20$ when purchasing drugs at private pharmacies. ${ }^{13}$ Soon after the beginning of the project university students-one of the two populations served by the participating health centres-went on summer leave for 3 months. Promotion of the kit was not allowed, thus leaving patients with urethritis largely unaware of its existence. Finally, where kits were sold directly by practitioners squabbling sometimes arose over the sharing of financial incentives among them. In fact, they expected to receive free samples and personal gifts from the project implementers rather than financial incentives.

Public health decision makers were reluctant to support the project. This reluctance originated in part from a belief that it had been imposed from the outside, especially after the change in government. The initial project had been to make MSTOP packages available in pharmacies without prescription. However, the planned widespread availability of MSTOP kits clashed with a medical community that favoured a more conservative strategy for addressing self treatment. MSTOP's role as a complement to, rather than a replacement for, primary health care in the formal sector was not understood.
In conclusion, the project mainly revealed that syndromic management of urethritis, straightforward though it may seem, was not readily accepted by healthcare providers. Reasons for non-acceptance should be further investigated. Over the counter sale of prepackaged therapy remains to be tested. However, public health authorities should first be aware of the limitations of the formal sector's response to STD care among men before this novel approach could be considered as an alternative strategy to inadequate self medication.

This research was supported by Family Health Internationa (FHI) and FHI's AIDS Control and Prevention Project under cooperative agreement number AID/DPE-5972-A-00-103100 at the United States Agency for International Development. Views expressed in the report do not necessarily reflect those of the funding agencies.

We would like to express our thanks to $\mathrm{Mr}$ Alexis Boupda-Kuate, AIDSCAP resident adviser in Cameroon, for Boupda-Kuate, AIDSCAP resident adviser in Cameroon, for Wim Wan Lerberghe of essor Wim Van Lerberghe of the Institute of Tropical Medicin for his valuable contribution to the design of the evaluation methodology of the project.

Dr M Laga contributed actively to the design and conduct of the study and revised the final version of the manuscript.

1 Holmes KK, Mardh P-A, Sparling PF, Wiesner PJ,E eds. Sexually transmitted diseases. 2nd ed. New York: MacGrawSexually transmitted diseases.
Hill, 1990:647-8,763-8.

2 Grosskurth H, Mosha F, Todd J, et al. Impact of improved treatment of sexually transmitted diseases on HIV infection in rural Tanzania: randomised controlled trial. Lancet 1995;346:530-6.

3 Amarro H, Gornemann I. Health care utilization for sexually transmitted diseases: influence of patient and provider characteristics. In: Wasserheit JN, Aral SO, Holmes KK, Hitchcock PJ, eds. Research issues in human behaviour and sexually transmitted diseases in the AIDS era. American Society for Microbiology, 1991:140-60.

4 Louis JP, Migliani R, Trebucq, et al. Prise en charge des maladies sexuellement transmissibles au Cameroun en milieu urbain en 1992. Ann Soc Belge Med Trop 1993;73: 267-78.

5 Van der Geest S. Self-care and the informal sale of drugs in south Cameroon. Soc Sci Med 1987;25:293-305.

6 Crabbé F, Carsauw H, Buvé A, et al. Why do men with urethritis in Cameroon prefer to seek care in the informal health sector? Genitourin Med 1996;72:220-2.

7 Gottlieb A, Mills J. Cefuroxime axetil for treatment of uncomplicated gonorrhea. Antimicrob Agents Chemother 1986;30:333-4.

8 Baddour LM, Gibbs RS, Mertz G, et al. Clinical comparison of single-oral-dose cefuroxime axetil and amoxicillin with probenecid for uncomplicated gonococcal infections in women. Antimicrob Agents Chemother 1988;33. 801-4.

9 Reynolds JEF, ed. Martindale, the extra pharmacopoeia. 30th ed. London: Pharmaceutical Press, 1993:137.

10 Centers for Disease Control and Prevention. 1993 Sexually transmitted diseases treatment guidelines. MMWR 1993 42(RR-14):56-60

11 World Health Organisation. Management of sexually transmitted diseases. Geneva: WHO, 1991

12 Management Sciences for Health. International drug price indicator guide. Arlington, VA, 1996.

13 Trebucq A, Louis JP, Tchupo JP, et al. Treatment regimens of STD patients in Cameroon; a need for intervention. Sex Transm Dis 1994;21:124-6. 